\title{
Correction to: Theoretical Fluid Dynamics
}

\section{Correction to:}

\section{A. Feldmeier, Theoretical Fluid Dynamics, Theoretical and Mathematical Physics, https://doi.org/10.1007/978-3-030-31022-6}

In the original version of this book, the following belated corrections have been incorporated:

Page 18, Eq. (2.54): replace $\mathrm{d} \vec{F}$ by $\mathrm{d} \vec{F}(\mathrm{~d} \vec{a})$.

Page 18: delete full sentence after boxed Eq. (2.55).

Page 34, item (d): add "and" before "using Gauss' theorem."

Page 213, Eqs. (6.21) and (6.23): replace $\oint$ by $\int$.

Page 214, Eqs. (6.25) and (6.27): replace $\oint$ by $\int$.

Page 215, Eq. (6.29): replace $\oint$ by $\int$.

The erratum book has been updated with the changes.

The updated version of these chapters can be found at https://doi.org/10.1007/978-3-030-31022-6_2

https://doi.org/10.1007/978-3-030-31022-6_6 